\title{
NOTE ON MERCURY LIGHT POLLUTION IN SPECTROSCOPIC OBSERVATIONS
}

HUANG CHANGCHUN

Purple Mountain Observatory, Academia Sinica, Nanjing, PRC

\begin{abstract}
Mercury light pollution has appeared in our spectroscopic observations of the Comet 1980 u made at the Observatoire de Haute Provence and spectroscopic observations of the Nova Andromeda 1986 made at the Purple Mountain Observatory. On spectra of an exposure of about one hour of the comet obtained at the $1.93 \mathrm{~m}$ telescope of the OHP using the image tube spectrograph $\mathrm{D}$ (dispersion of $92 \mathrm{~A} / \mathrm{mm}$ ), the lines 4358,4047 of $\mathrm{HgI}$ are very strong. In the case of the nova, these lines are quite noticeable on spectra of exposure of 3 hours obtained at the $0.6 \mathrm{~m}$ telescope of the PMO with the Marly-Nanjing spectrograph (dispersion 40 $\mathrm{A} / \mathrm{mm}$ ).
\end{abstract}

